\title{
The Novice Voyage: Challenges Experienced by Social Workers in their First Year of Full Employment
}

\author{
Victor C. Huni \\ Master of Arts in Social development Student, Department of Social Work, \\ University of the Witwatersrand, South Africa. \\ Email: victorhuni@gmail.com \\ Victor Chikadzi (PhD) \\ Lecturer Department of Social Work, \\ University of the Witwatersrand, South Africa. Victor. \\ Email: Victor.Chikadzi@wits.ac.za
}

\section{Doi:10.5901/mjss.2014.v5n14p465}

\begin{abstract}
The transition from university to work is no doubt an issue of paramount importance considering the ever changing business and working environment. The process entails change and adaptation to new situations and circumstances that dictate basic skills needed for the successful transition to the workplace setting. In the process of transition from university to work, many graduates are confronted with challenges that deter them from thriving as labour entrants. This has raised concerns on whether university training and education equips graduates with necessary competencies to overcome challenges during the transition period. Against this backdrop, this paper explores the challenges that graduate social workers face in their first year of full employment as they transition to the work environment. Insights gleaned from this qualitative study show that graduate social workers experience several challenges in their first year of full employment which strains the transition process from university to work. These challenges include among other things, Age disparity between newly qualified social workers and their clients, poor orientation practices, inadequate resources to carry out tasks, poor supervision practices, and work overload. The findings of this study are vital in guiding adjustments of social work settings to smoothen the University to work transition by newly qualified social workers.
\end{abstract}

Keywords: university, work, transition, challenges, social workers.

\section{Introduction}

Life transitions occur several times in our lives and managing them can be emotionally taxing given that they represent the end and beginning of something. They involve how people respond to change overtime. For university graduates, it is the end of formal education and the beginning of work life. Schumacher and Meleis (1994 as cited in Kralik, Visentin \& Van Loon, 2006: 321) posit that, "the meanings of change that people have, expectations of events, level of knowledge and skill, availability of new knowledge about a change event, resources available in the environment, capacity to plan for change, and emotional and physical wellbeing all have an impact on transitions." Transition is a complex process that is significant and often difficult for undergraduate job entrants (Holton, 2004 as cited in Wendlandt \& Rochlen, 2008). This is exacerbated by the ever changing business and working environment propelled by technological advancements and globalisation which continues to reshape job characteristics and ultimately leaves graduate job entrants with feelings of stress, anxiety, shock, fear, uncertainty, loneliness, depression and low self-esteem (Perrone \& Vickers, 2003). The transition process thus becomes less predictable for graduates in their quest to establish a professional identity in the labour market. And given the importance of social work in improving social and community functioning, this notion becomes central in the transition of graduate social workers to workplace environments. Against this background, this article explores the challenges that confront social work undergraduate job entrants as they transition from university to work environment. Dramatic shifts in the nature of employment in different social service agencies point to the diverse range of competencies needed for success in social work practice. 


\section{Literature Review}

\subsection{The context of university to work transition to work}

Transition from university to work does not occur in isolation of other external factors that contribute to issues that influence the transition process. These factors map out the expedition of an undergraduate into the world of work and depict the context in which youth transition to work occurs. As such, the context of youth transition to work encapsulates various issues that are important to consider when exploring this phenomenon.

Labour market conditions also speak directly to the context of youth transition to work given their role in regulating interaction between workers and employers. "The labour market provides a structure through which workers and employers interact in relation to jobs, working conditions and pay." (Eurofound, 2014). Hence it plays an important role in shaping the transition process for graduate students. Muller and Gangl (2003: 9) echo this view by highlighting that "the experiences of young people in making transition from school to work are particularly likely to be affected by varying contextual circumstances" and these include the labour market conditions. In abstract terms, the labour market conditions are captured by market forces of skills supply and demand which result from interaction of economic, structural and policy factors. The economic factors characterize the demand of goods and services which stimulate production and in turn create employment. The structural factors reflect employment opportunities based on skills supply and demand in the labour market. The policy factors are regulatory mechanisms put in place by the government to control economic outcomes and labour relations (ILO, 2011).

There is evidence to show that the labour market conditions can stifle the transition process of graduate job entrants if conditions do not favour employee growth and investment. In Africa, young people remain out of work for long periods before finding their first job making them vulnerable to unsuccessful transition to work. In the same vein, there is a growing population of youth who are exerting more pressure on the labour market for new job entrants whilst on the other hand market forces are failing to create enough job opportunities for young people (Garcia \& Fares, 2008). In addition, economic uncertainty and rapid social changes characterized by technological advancement and globalisation perpetuate the complexity of the transition process. Ultimately, it limits opportunities for young people to advance themselves and as such unemployment rates among youth continue to increase inevitably which positions them in a vulnerable situation of experiencing an unsuccessful transition process. Youth entering the labour market therefore face a daunting task of overcoming challenges in their quest to establish a professional identity and integrate successfully in the labour market.

In light of the complexity of university to work transition discussed above, helping professions such as social work, nursing and occupational therapy are mostly affected by labour market conditions due to limited employment opportunities, low paying salaries and poor working conditions (Le Maistre \& Pare, 2004). This puts helping professions in a precarious position as they attempt to establish a professional identity during the transition from university to work.

\subsection{Understanding youth transition to work}

Understanding youth transition to work helps to reflect on the basic fundamentals of how transition is experienced by graduates. Perrone \& Vickers (2003) and Gaham \& McKenzie (1995) explored the dynamics of university to work transition to understand how graduates react and respond to the transition process. They reveal several clearly defined dynamics of transition to work which are not necessarily conclusive in all contexts of transition but generally confront most youths of today in various ways as they enter the labour market. These dynamics include:

\subsubsection{Culture change}

Individuals experience feelings of being overwhelmed and uncertainty when leaving university. Many newly qualified graduates are usually unprepared for the significant, life-impacting decisions and options that confront them. Scholars such Gaham \& McKenzie (1995) note that in many instances graduate workers are required to adopt the fundamental values and beliefs of their new employing organisation which differs from those held on campus. On the other hand, they are often undecided about their career ambitions as they do not have an accurate assessment of their personal skills as well as an understanding how their personal qualities can fit into a prospective employer's expectations. High employment rates among youth across the world also reflect labour market uncertainty and hence present challenges that will confront youth as they endeavour to enter the labour market. The transition from University to work has therefore moved from being predictable to becoming a more complex process in which many graduates become vulnerable to 
unemployment and feelings of being overwhelmed and uncertainty when leaving university (Stewart, 2004).

\subsubsection{Inflated expectations}

Candy \& Crebert (1991: 572), posit that "the new graduate entering an unfamiliar work setting is confronted with reality shock, when expectations and actual experience of the new job do not match". New graduates have ideal type of jobs that appeal to them and as such form their own perceptions of what they expect to find in their new workplaces. In most cases, graduates find their expectations about where their qualification will take them grossly overestimated. There is a mistaken belief among university students that if one obtains a degree; one is guaranteed to get the perfect job. And clearly, completing tertiary education creates expectations for students with regards to labour market entry. Job status and wages are the most common reasons for job dissatisfaction which derive from inflated expectations of graduate employees (Perrone \& Vickers, 2003). These assumptions that are held by most university graduates imply that a successful transition to work is dependent on whether employee's expectations and the actual job experience match.

\subsubsection{The work experience paradox and how education prepares graduates for work}

Prospective employers have a paradoxical expectation that university graduates should have substantial work experience. "Graduates need to get a job to gain required experience, while employers continually assert the need for significant work experience in addition to their degree to secure an entry level graduate position" (Perrone \& Vickers, 2003, p. 74). In this case, gaining some work experience while still at university gives one an advantage of securing an entry level graduate position given that it equips them with skills necessary for work in full-time employment. Employers thus take work experience into consideration in the process of recruiting a new employee. This implies that employers view that tertiary education on its own does not guarantee entry into the labour market. However, Kitchener \& Brener (1998 as cited in Perrone \& Vickers, 2003) express their scepticism about this approach pointing out that most newly qualified youths may not have the level of maturity demanded from students in learning from the world of work. Furthermore, part-time work for students may not always be useful in equipping students with communication skills and other related skills needed in employment because the nature of the job does not build that. In this case, most students occupy unskilled positions which do not develop any skills necessary for professional practice (Holmes, 1999). Against this, the work experience paradox makes the transition process to work life complex for young people with employers tightening their recruitment strategies to select skilled graduate employees which in turn creates stiff competition for jobs and limited opportunities for employment. On the other hand, Gaham \& McKenzie (1995) outline the basic premise of work experience focusing on matching skills and knowledge to ease the transition process. This has implications for workplace learning during the tenure of an undergraduate course to facilitate the process of acquiring skills needed for work matching them with knowledge acquired. Candy \& Crebert (1991) summarise this conception pointing out that universities and workplaces distinctively orient learners and employees to achieve their goals in different ways. Universities are educational in intent while in workplace it is more of applying what has been learnt.

In light of the above dynamics that speak to the notion of university to work transition, it is evident that the process involves difficulties that can confine graduates from reaching their full potential in their quest to establish a professional identity. The outcomes of the transition process have far reaching implications for developmental needs of graduates whose quality of life is based on job satisfaction and job rewards.

\section{Methodology}

\subsection{Aim}

The aim of the study was to explore the challenges faced by social workers in their first year of full employment.

\subsection{Research approach and design}

A qualitative exploratory approach was utilized in this study. Given that we were looking for meanings, experiences and characteristics of the transition process from university to work, the qualitative approach was deemed to be appropriate. The basis of this approach is that it focuses on the meanings and understanding of life which emerge from people's life experiences (Denzin \& Lincoln, 1998). It allows for examination of how people learn about and make sense of themselves and others (Babbie, 2011). The study employed an exploratory research design. Exploratory studies help in answering 
questions regarding "how social experience is created and given meaning" and it is through this process that insight is gained into participants' subjective experiences (Denzin \& Lincoln, 1998: 8). Moreover, exploratory research is commonly utilised when little is known about the topic under study and often raises questions to be investigated by more extensive studies in the future (Marlow \& Boone, 2005).

\subsection{Sample and sampling procedure}

Nine social workers in their first year of full employment were selected via convenience sampling. Convenience sampling is based on availability of participants who fit the characteristics sought by the researcher (Babbie, 2011). The criterion for the selection of participants was that all participants had to have a Bachelor of Social Work degree completed from an accredited higher education institution and had to be employed staff members who are in their $1^{\text {st }}$ year of full employment.

\subsection{Data collection method and tools}

In-depth semi-structured interviews were employed during data collection. The interviews were tape recorded to avoid data loss. Interviews as a method of data collection offer more flexibility to both researcher and the participants and enable in-depth responses and clarification of meaning (De Vos et al, 2002). The duration of each interview was approximately forty minutes. The interviews were guided by a set of open questions which prompted discussion on specific areas of interest in the study. Greef (2002) points out that an interviews schedule enables the researcher to cover specific question areas.

\subsection{Data analysis}

Thematic content analysis was used to analyse the data collected during the interviews. It is a "method of identifying, analysing and reporting patterns within data" (Braun \& Clarke, 2006, p. 79). In thematic content analysis the researcher examines closely the content and words used by respondents in an interview to detect patterns or themes that will be used to determine the findings of the research study. Thematic content analysis is empirical in orientation and aims to make valid inferences from data into a context which may be replicated (Krippendorf, 1980).

\section{Findings and Discussion}

The findings of the study show that graduate social workers are confronted with several challenges that strain their transition process from university to work and ultimately stifle their professional development. Below is a discussion of the key findings emanating from the study.

\subsection{Age disparity between newly qualified social workers and their clients}

Age disparity in workplace relationships is a central issue in organisational effectiveness. There are cultural, societal and religious issues that define ways in which service providers and clientele relate to each other, particularly on issues of race, gender, marriage and sex. These sometimes present barriers in provision of quality services to clients and thus result in feelings of anxiety and frustration for the service provider which deters the organisation's effectiveness. The findings of this study reveal that there were difficulties in establishing relationships with clients. The age disparity between the newly employed social workers and the clients that they encountered in work settings was significant and hence presented a major challenge for graduate social workers in establishing professional relationships. This was mainly attributed to cultural norms and values which subscribe to the notion that help or any form of social work services provided to clients must be rendered by an older person. One participant mentioned that:

"...to speak to people older than me particularly about matters related to the bedroom, sex, HIV and things like that (was a challenge)... I could feel it that I am not comfortable here and at times you don't even know whether it shows on your face that can they see that you are uncomfortable because you can see in their eyes that people are uncomfortable to talk to a young person about such matters so I think the challenge for me was speaking to elderly people about matters of the bedroom" 
Most social work graduates qualify at an early age and they are called upon to work with matured and aged clients. Youthfulness is associated with being a novice; as a result mature clients become skeptical about the competence of young social workers. Lum (2010) notes that working with older clients in social work practice has been proven to be a daunting task for young social workers owing to cultural values and beliefs. Notably, African cultures view the elderly as the wisest in a community or society and are therefore in a position to offer the best solutions to problem situations in families and individuals. Some African cultures also forbid young people from discussing about certain taboo issues, such as sex related matters. Social workers who subscribe to some of these cultural values and beliefs find themselves in a cultural dilemma which in turn presents as a major challenge in transition process from university to work. If the competence of a social worker is questioned due to their age, this may have adverse effects on their self-esteem which may negatively impact on the quality of help they render to clients. It is therefore important that in such contexts, matured social workers need to assure clients during enrolment about the professional competencies of youthful social workers despite their age. This would no doubt help to ease some tensions resulting from age disparity. Youthful social workers also need to be trained to be more assertive and discuss such concerns with clients at the beginning of the helping relationship. Such support would no doubt help to support the university to work transition of newly qualified social work graduates. It may also be helpful to gradually involve newly qualified social workers in complex cases as they may not have matured enough to handle them. Perrone \& Vickers (2003) note that, most social work graduates are young and therefore lack the level of maturity demanded in handling complex cases in their work settings at the time they start practicing.

\subsection{Generation gaps lead to clashes in operational philosophy:}

Age difference amongst employees in workplaces conjures up another important issue in workplace relations. The ever changing technological advancements in workplaces and societal relations between and amongst the young and elderly continues to reshape how we achieve specific goals in all spheres of our lives. This results in conflict of interests amongst employees and thus may affect the motivation for one to carry out job tasks successfully. Participants highlighted the challenges they faced in establishing professional relationships with co-workers and/or superiors in their work settings. The significant differences in age gaps between newly employed social workers and those that were already established within the organization resulted in conflict of mindsets and work patterns. One research participant asserted that,

"the age gaps in the profession is a challenge...you come in and you are young and you have people who have been 10,15 or 20 years as social workers they know certain ways of working, you know certain ways that you were told you were going to use at work so then there is that gap of how you meet in-between"

In a way, this holds back the newly employed social workers because they are unable to established their own work patterns in the organisation and therefore find it difficult to adjust to the new environment in which personal initiative is discouraged. Participants felt that such a culture of working threatens to nullify the relevance of skills learned in university merely because organisations want to stick to old ways of carrying out work activities. This was clearly spelt by a research participant in which he highlighted how this becomes a challenge in the work setting:

"...you come in as a young person knowing technology, knowing media, knowing that the world is fast and you realize people still want tons of paperwork, tons of just taking a long way around things when you have faster ways of doing this, so there is always that clash"

The issue of generation gaps between professionals within an organization is thus problematic for job entrants in professional practice of social work. This finding is corroborated by Tolbize (2008) who notes that the perceived elements of success in the workplace are different from generation to generation. This has created frictions between new employees and old employees which are largely aggravated by new technology and work patterns. It is inevitable, then for the transition process from university to work to be disrupted by these differences that create frictions between newly employed social workers and old employees.

\subsection{Poor orientation practices}

The issue of orientation serves an important purpose in workplaces. It is meant to familiarize new members with their workplace environment to include them as part of an existing group of employees in the organization. However a majority of the participants voiced out their discontent over their orientation experience into their workplace which prevented them 
from utilizing their abilities to the fullest potential in their first year of full employment. Many participants felt that Social service agencies were not providing the required support systems to newly qualified graduate social work employees on what the job entails and how the job tasks can be completed. Essentially, this implies that the transition process from university to work is disrupted and social work job entrants are confronted with the challenge of working in an organisation without a clear understanding of how to complete job tasks and coming to terms with the fact that the organization does not have internal resources to provide support to its employees. Referring to the orientation experience, one participant expressed her discontent, she argued that:

\begin{abstract}
"the orientation was very bad, when I got here I was introduced to everyone it was very basic, some of the things I had to learn on my own when I did mistakes, cause I didn't know some of the things"
\end{abstract}

Similarly another participant asserted that,

"I really felt like I was not even orientated because only a few things were (explained) because of the demand of the work...at the time when I was supposed to be fully incorporated to the field, there was work that needed to be looked at... without the full orientation on how to do some of the things"

Lack of proper orientation to organizations is thus an important issue that explains why new social work employees struggle to integrate themselves in the labour market after they complete their degree. Savickas (1999) posits that orientating students to their new workplace increases their awareness of task to be encountered and decisions to be made and this encourages them to take initiative in how they cope with the task by adopting certain attitudes and behaviors Given the importance of orientation, it is clear that omitting rigorous employee orientation in organizations impedes the newly qualified social worker employees' process of adjusting to their new surroundings.

\title{
4.4 Inadequate resources and support systems
}

Support systems and resources in workplaces are important because they provide employees the space in which they can carry out job tasks successfully. They enable employees to deliver services to service users in an effective and efficient way. In contrast, a lack of resources and support systems results in job dissatisfaction and less work productivity. This concern was raised by most participants who expressed their frustration due to lack of resources and support systems to enable new employees to practice to their fullest potential. One participant pointed out the challenge of having to work with clients without an office:

"I waited for a year to have my own office so I had to share an office with somebody else and same thing with a computer, so that was a challenge"

Similarly one participant remarked that,

"I find it difficult that we end up having less resources, we end up being underpaid because I feel there is an undermining from the structural level, so you will find that you don't have facilities such as offices, computers whereas you are expected to deliver....and I think we suffer because sometimes I have to wait for someone to finish using a computer you know things like that... that at times de-motivates me..."

In this case new qualified social workers find it difficult to cope with the fact that they are not offering the best possible help to clients. While they are not personally at fault for it, such a status quo is bound to emotionally affect and frustrate them making the transition from university to work a stressful and difficult one. Evidence also shows that lack of support systems in workplaces results in job dissatisfaction and high job turn over. Scholars such as Bakker, Hakanen, Jari \& Xanthoulou (2007) note that lack of job resources decreases worker engagement, particularly when job demands are high.

\subsection{Poor supervision practices}

Supervision in workplaces serves an important purpose in guiding employees' workplace activities. More importantly, it maintains a central position in the field of social work practice. Tsui \& Ho (1997) note that supervision plays a crucial role in determining job satisfaction levels of social workers. Nonetheless, the findings of this study show that some of the participants were discontent with the quality of supervision they received from their supervisors. They particularly 
described how supervisors neglect their feelings putting more emphasis on worker production and the situation of the client systems. One participant described the nature of supervision in her organisation:

"...there are supervisors, when I am having my supervision sessions I talk about clients I never talk about how I am feeling."

\section{Another participant also mentioned that:}

"...the supervision mainly focused on have I been able to get all the cases done? Rather than how are you feeling?"

It is clear from the about verbatim quotes that supervision of newly qualified social workers narrowly focuses on work targets and processes rather that looking at supervision from a holistic perspective. There is a need for supervision practices that are premised on the fact that the supervisees' work is best supported by supporting their emotional and professional well-being. It is clear from the above that lack of holistic supervision which also takes into account the needs of novice social workers in organisations results in burn out and affects the professional development of employees. This hinders the primary area of growth of an employee which involves achieving and developing a high level of competence. It also increases job dissatisfaction and job turn over.

\subsection{Work overload}

The nature of tasks done at work is highly significant in determining employee wellbeing as well as levels of job satisfaction. It is therefore important to carefully consider one's ability to carry out specific job tasks when designing job tasks and characteristics. Failure to do so may result in several negative outcomes for the individual employee and the employing organisation. In this case, work overload is a well-known notion in workplaces that largely contributes to deterioration of employee wellbeing and levels of job satisfaction. This is one issue that most participants pointed out in explaining how their transition from university to work was an unsettling experience. Participants highlighted that in most cases, they are not given breathing space for them to find their feet by their employers. They are required to start with their work immediately after entering the organization. This is certainly challenging for most participants who have to come to terms with the reality of practising social work as a full time employee. In that respect, work overload emerged as a dominant aspect of the challenges that were faced by social workers in their first year of full employment. The amount of work that most participants do in their respective organisations requires excessive physical and mental effort. One participant pointed out that:

\footnotetext{
"the child welfare in ...... my first day there I think I was given 90 files and they said that was my case load and then they explained to me why it is 90 ...they said that no one was attending to the work and told me it's because the previous people were very bad at their job and then they gave me the task on going through each file."
}

The issue of work overload was also highlighted by the participants who were at discomfort with the amount of work that they were required to do. One participant mentioned that:

"The work is too much, and here you have to know everything, you have to type reports and every day you have to see a client so it's challenging"

Based on the accounts by participants above, the issue of work overload is one that is prominent in the profession of social work given the high number of social problems that occur in our society. This is further aggravated by the shortage of social workers in South Africa and as a consequence the available social workers are left to deal with a large number of social problems. The effects of work overload are felt by social work employees. Fisher, Katz, Milner and Thatcher (2003: 137) point out that work overload "leads to excessive demands on time and may lead to feelings of uncertainty about one's own ability to perform any of the roles properly." This explains why newly employed social workers may struggle to settle in their new workplace thereby negatively affecting the transition from university to work.

\subsection{Reality shock}

The concept of reality shock speaks to experiences encountered by new graduate employees in which their view of what work entails differs from status quo in workplaces. Employees were confronted by job tasks they had never encountered 
or trained for in higher tertiary institutions. In the same way the new employees were also confronted with reality shock in which their expectations and the actual experience of the new job did not match. One participant mentioned that

"my role as a social worker is slightly different from what I anticipated when I finished my degree, whatever we learn in varsity we only use maybe $30 \%$ of it. I was never taught about statutory work I only learned it here. Like we did do it but it was theoretically based, we didn't do practical we were not going to court I never had that when I was doing my practical's I never went to court. So when I got here I got the shock of my life because I didn't know anything. I had to learn as if I didn't go to varsity"

Similarly another participant shared the same sentiments highlighting job task he had never encountered or trained for in higher tertiary institution education. He mentioned that,

"adjusting to the work itself, you know...there were a lot of things that were new, for example I had never removed children before, so there was this fear that if I remove somebody's child into foster care etc is this person going to come after me or do something to me..."

It is clear from the above views by participants that in some cases expectations that newly qualified social workers have are not always matched by the reality on the ground and this leads to shock that in a way unsettles them. Consequently, this may result in discontent which affects how graduate social workers get to settle in their first year of employment which may in turn negatively impact on job performance. There is evidence that reveal that expectations play an important part in actual job performance, attitudes and habits (Graham \& McKenzie, 1995). As such, organisations that fail to meet employees' expectations are likely to yield low performance and undesirable attitudes and habits from employees. In essence, the transition process to the workplace is disrupted. However, one should also be mindful that some of the expectations that employees have on certain organisations are unrealistic and therefore must be reshaped by the recruiting organisations.

\section{Conclusion}

The findings discussed above point to a gloomy university to work transition for newly qualified graduate social workers. It is clear that the settings from which the participants were interviewed did not have conducive work environments and operational systems that allow for a smooth university to work transition for newly qualified social workers. The results of the study point towards the need for legislating basic minimum standards and conditions under which new entrants to the social work profession must work. The work done by social workers affect people lives. To this end, the proper wellbeing and functioning of social workers within the workplace must be one of the uppermost considerations. There is a definite need to care for carers first before they can care for others. Challenges such as high workloads, inadequate orientation practices and poor quality supervision and support of newly qualified social workers if not addressed will lead to lack of job satisfaction, poor on the job performance and low morale. In some cases, some social workers may end up living the profession altogether to work in other fields which will put a strain on the human resources within the social services field given the crippling shortage of social workers in South Africa at present. Consequently, there is a need for adjusting employment practices of newly qualified social workers to ensure that they are given the best start possible which will support their professional growth and maturity as frontline workers within the social welfare arena.

\section{References}

Babbie, E. (2011). Introduction to Social Research. (5 $5^{\text {th }}$ Ed). Canada: Wadsworth Cengage Learning.

Bakker, A. B., Hakanen, J. J., Demerouti, E. and Xanthopoulou, D. (2007). Job Resources Boost Work Engagement, Particularly when Job Demands are High. Journal of Educational Psychology, 99(2), 274-284.

Braun, V. and Clarke, C. (2006). Using Thematic Analysis in Psychology. Qualitative Research in Psychology, 3(2), 77-101.

Candy, P. C. \& Crebert, R. G. (1991). Ivory Tower to Concrete Jungle: The Difficult Transition from Academy to Workplace as Learning Environments. The Journal of Higher Education, 62(5), 570-592.

Denzin, N. and Lincoln, Y. S. (1998). Collecting and Interpreting Qualitative Materials. Thousand Oaks: Sage.

De vos, A. S., Stydom, H., Fouche, C. B., and Delport, C.S.L. (2002). Research at Grassroots. For Social Sciences and Human Service Professions. (2nd ed). Pretoria: Van Schaik Publishers.

Eurofound (2014). Labour Market. Retrieved 16 April 2014 from https://eurofound.europa.eu/areas/labourmarket/index.htm

Fisher, J., Katz, L. A., Milner, K. and Thatcher, A. (2003). South Africa at Work: Applying psychology to organisations. South Africa: Witwatersrand University Press. 
Garcia, M. and Fares, J. (2008). Youth in Africa's Labour Market. Washington: The International Bank for Reconstruction and Development.

Graham,C. and McKenzie, A. (1995). Delivering the promise: the transition from higher education to work. Education + Training, 37(1), 4-11.

Greef, M. (2002). Information Collection Interviewing. In de Vos, A., Strydom, H., Fouche, C., and Delport, C.S.L. (Eds). Research at Grassroots: For the Social Sciences and Human Service Professions. (2nd Ed). Pretoria: Van Schaik Publishers.

Holmes, L. (1999). Competence and capability: from confidence trick to the construction of the graduate identity. In O'Reilly, D., Cunningham, L. and Lester, S. (Eds.), Developing the Capable Practitioner: Professional Capability through Higher Education. London: Kogan Page.

Kralik, D., Visentin, K. and Van Loon, A. (2006). Transition: A literature review. Journal of Advanced Nursing, 55(3), 320-329.

Krippendorff, K. (1980). Content analysis: An introduction to its methodology. London: Sage.

International Labour Organisation. (2011). An introductory guide for employers' organisations: tackling youth employment challenges, an overview of possible actions and policy considerations. Turin: International Training Centre of ILO.

Le Maistre, C. and Pare, A. (2004). Learning in two communities: the challenge of universities and workplaces. Journal of Workplace Learning, 16(1/2), 44-52.

Lum, D. (2010). Culturally Competent Practice: A framework for understanding diverse groups and justice issues. (4th Ed). USA: Brooks/Cole Cengage Learning.

Marlow, C. R. and Boone, S. (2005). Research Methods for Generalist Social Work. (4th Ed). Canada: Thomson Brooks/Cole.

Muller, W. and Gangl, M. (2003). Transition from Education to Work in Europe: The Integration of Youth into EU Labour Markets. New York: Oxford University Press.

Perrone, L. and Vickers, M. H. (2003) "Life after graduation as a "very uncomfortable world": an Australian case study". Education + Training, 45(2), $69-78$.

Savickas, M. L. (1999). The Transition from School to Work: A Developmental Perspective. The Career Development Quarterly, 47(4), 326-336.

Stewart, J. (2004) The importance of youth employment in a globalizing world: the ILO viewpoint. Paper presented to Symposium on Globalization and the Future of Youth in Asia, Tokyo.

Tolbize, A. (2008). Generational Differences in the Workplace: Research and Training Centre on Community Living. Retrieved October 31, 2012 from http://rtc.umn.edu/docs/2_18_Gen_diff_workplace.pdf.

Tsui, M. S. and Ho, W. S. (1997). In search of a comprehensive model of social work supervision. The Clinical Supervisor, 16(2), 181205.

Wendlandt, N. M. \& Rochlen, A. B. (2008) Addressing the College-to-Work Transition: Implications for University Career Counsellors. Journal of Career Development, 35(2), 151-165. 